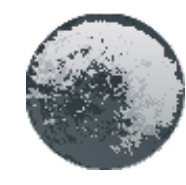

\title{
METAVISUAL STRATEGY FOR THE BUILD AND REBUILDING OF CHEMICAL CONCEPTS IN THE SYMBOLIC LEVEL WITH THE ASSISTANCE OF IMAGES
}

\author{
Solange Locatelli, Agnaldo Arroio \\ University of São Paulo, São Paulo, Brazil
}

\begin{abstract}
Considering the opportunity of reconstruction of ideas is very important for success in the learning process. For this purpose, a metavisual strategy was used, comparing images, one made by the students and the other presented by the researcher so they could compare and be able to rebuild their ideas, the latter an image based on a scientific accepted model. The research focus was the comprehension of the symbolic level by the learners while studying two electrochemical interactions by comparing images and rethinking about them. Thirty-two high school students, organized in pairs, participated in the research carrying out a proposed teaching and learning sequence (TLS) in the classroom. First, the students proposed hypotheses and then they had the opportunity to rethink about them modeling their learning. Students were filmed and the transcriptions and registers made by them were analyzed later. The results indicate a qualitative and progressive improvement in the learning of the subject when using the metavisual strategy, bringing evidence that it can be efficient to build and rebuild initial concepts in electrochemistry.
\end{abstract}

Key words: electrochemical teaching, metacognition, metavisualization, metavisual strategy, modeling.

\section{Introduction}

In a simple way, metacognition refers to thinking about your own thinking. By extending this concept, it can be said that metacognition refers to the monitoring and selfregulation of cognitive processes (Flavell 1976) and to consider metacognitive strategies to self-regulate this encoding leading to effective learning becomes increasingly important (Locatelli \& Arroio, 2013). This paper will be focused on the rethinking of images, which is the metavisualization, a term proposed by Gilbert (2005). For allowing reconstruction of ideas, self-regulation, the use of metacognitive strategies has been growing in science education, especially in chemistry. Specifically regarding electrochemistry, studies indicate a great difficulty in learning this topic in general (Obomanu \& Onuoha, 2012; Rosenthal \& Sanger, 2012; Schmidt, Marohn \& Harrison, 2007). In particular, Obomanu \& Onuoha (2012) point out a difficulty of students in understanding the half-equations that occur in electrodes. Thereby, this paper intends to contribute to a greater understanding of how to think about the visualizations (metavisualization) may relate to the learning of electrochemistry, considering the triplet representation, specifically the symbolic (in this case, the chemical equations). Chittleborough \& Treagust (2008) state that for students to interpret chemical diagrams, connecting these various levels (triplet), the use of metavisual skills is needed, and to make those connections are not always explicit to them. Regarding the symbolic representation, it provides a quantitative explanation of the phenomenon, 
with symbols that represent the interactions between the atoms, ions or molecules, or even balanced chemical equations representing the chemical interactions occurring (Gilbert \& Treagust, 2009). Also, in relation specifically to the symbolic level, Taber (2009) says that sometimes the student may even be thinking right, but he does not express through the symbols that represent chemical concepts. Another interesting point is that the use of chemical symbolism becomes more complex and the cognitive demand to understand it.

\section{Purpose of the Research}

The aim of the research is not to generalize, but to understand the process of rebuilding concepts in electrochemistry by the 16-18 aged students, specifically the symbolic level. This is an empirical qualitative interpretative study, which was conducted in a private school in São Paulo city in Brazil. Then, this research intends to provide answers to the following question: To what extent to rethink the images (to metavisualize) may contribute to (re) build of explicative models in the symbolic level?

\section{Methodology of Research}

\section{Research Participants}

Thirty-two 16-18 aged students from a private school of Sao Paulo city participated in this research. They were beginning their studies in electrochemistry and the proposed teaching and learning sequence (TLS) was carried out for two lessons of 50 minutes each. Students were oriented to work in pairs and to propose explanatory hypotheses without consulting any material, they could only discuss among them, that first time. In the next lesson, the teacher of the class made a collective discussion.

\section{Instruments}

Students were filmed performing the teaching and learning sequence and the records were transcribed later. Furthermore, the drawings they made were also collected for analysis. Later a semi-structured questionnaire regarding the perception of these students was applied.

Another important guideline was that they should speak aloud everything they were thinking, technique known as "think aloud", often used to attempt to register at least part of metacognitive thinking. The orientation of this technique is important to be given specifically because thinking aloud is not familiar to students (Ericsson \& Simon, 1993).

\section{Teaching and Learning Sequence (TLS) Proposed}

In the teaching and learning sequence (TLS) to compose this research, the chemical interactions that were investigated are described and illustrated in Figure 1. 


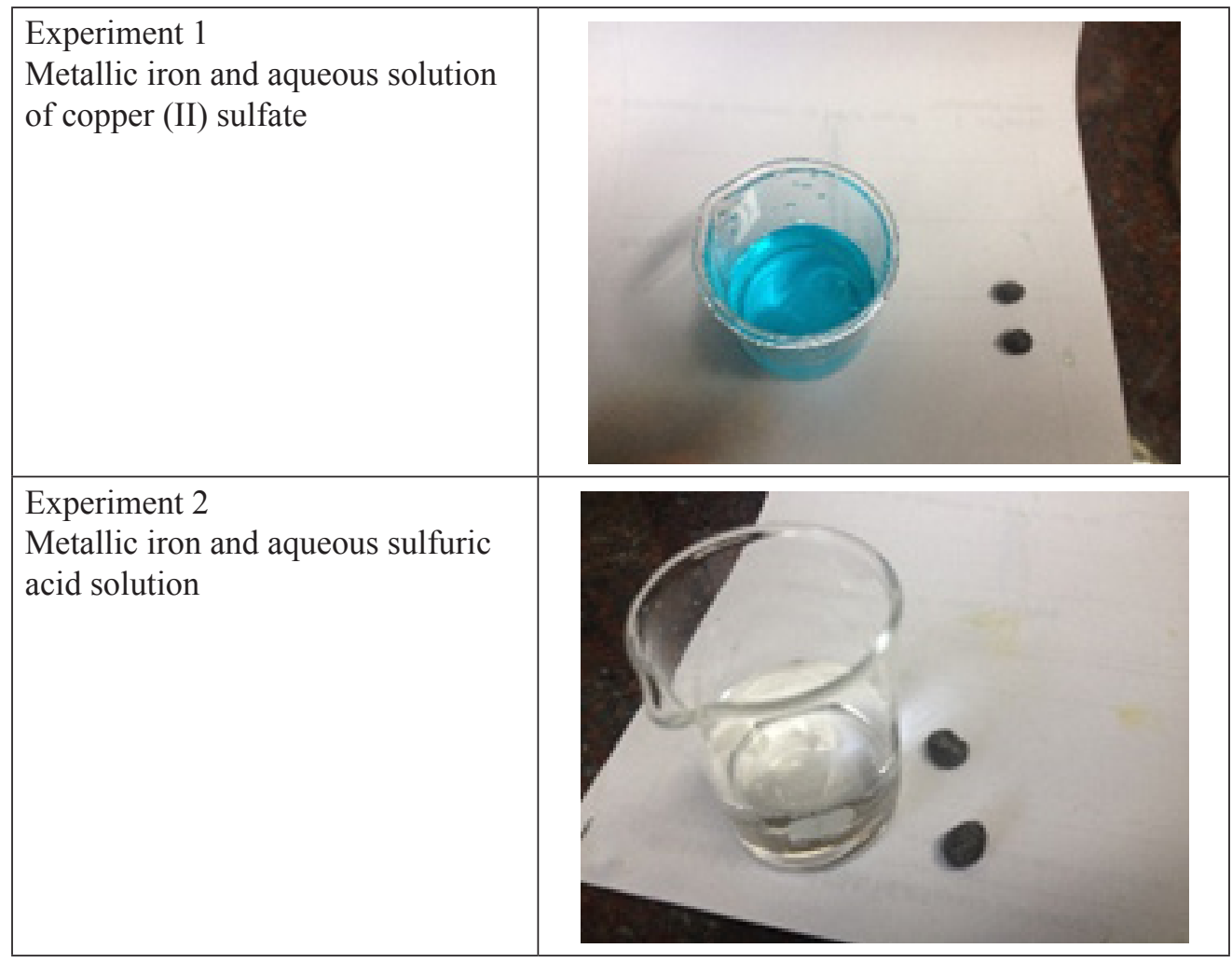

Figure 1: Description and illustration of the experiments 1 and 2.

Both experiments ( 1 and 2$)$ were divided into two parts. Part A (1A and $2 \mathrm{~A})$ was the moment in which the students had proposed hypotheses and part B (1B and $2 \mathrm{~B})$, the metacognitive stage, where they had to compare what they had done with an image presented to them, as can be summarized in Table 01:

Table 1. Experiment parts.

\begin{tabular}{|l|l|l|l|}
\hline \multicolumn{2}{|c|}{ Experiment 1 } & \multicolumn{2}{|c|}{ Experiment 2 } \\
\hline \multicolumn{1}{|c|}{ 1A } & \multicolumn{1}{|c|}{ 1B } & \multicolumn{1}{c|}{ 2A } \\
\hline $\begin{array}{l}\text { Hypothesis by stu- } \\
\text { dents - first experi- } \\
\text { ment }\end{array}$ & $\begin{array}{l}\text { Hypotheses re- } \\
\text { thought by students } \\
\text { after metavisual step } \\
\text { - first experiment }\end{array}$ & $\begin{array}{l}\text { Hypothesis by stu- } \\
\text { dents - second ex- } \\
\text { periment }\end{array}$ & $\begin{array}{l}\text { Hypotheses re } \\
\text { thought by students } \\
\text { after metavisual step } \\
- \text { second experiment }\end{array}$ \\
\hline
\end{tabular}

Initiating the teaching and learning sequence (TLS), the students predicted what they thought it would happen to both experiments. After they observed, proposed a hypothesis on a symbolic level (1 A and $2 \mathrm{~A}$ ) and rethought, using an image consisting of a possible equation and submicroscopic level drawing for comparison with their proposal - metavisual step (1B and 2B), as can be exemplified in Figure 2 with respect to the first experiment. 


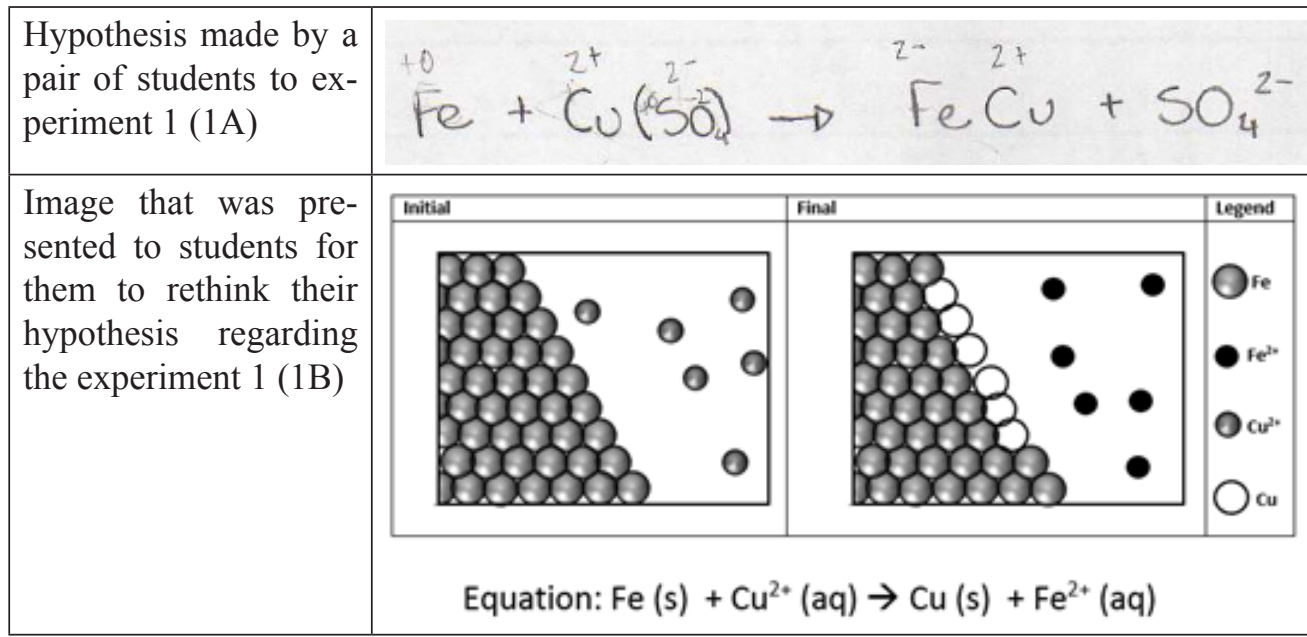

Figure 2: Hypothesis made by students ( $1^{\text {st }}$ line) and image presented to them to rethink - metavisual step ( $2^{\text {nd }}$ line $)$.

\section{Data Analysis}

For the data analysis, three categories were created to verify that each explanatory model proposed by students (symbolic I and II, Parts A and B) approached the scientifically accepted model. They are as follows:

Correct (C): from the analysis of all the hypotheses proposed by the 16 groups, the equation was considered correct if it approached the scientific model.

Partially correct (PC): This category was developed in order to verify if to some extent they could properly represent the phenomenon. Thus, to belong to this category, the hypothesis of students (chemical equation) must show evidence that they have understood the exchange of electrons between the iron atom and the copper ion, which has been indicated for example, by explicit variation of the oxidation number or have been observed this evidence in their speech.

Incorrect (I): it is far from scientifically correct model. In this category are the cases in which the suggested product is different or non-existent and / or has not been shown evidence of the exchange of electrons between the copper ion and iron atom.

\section{Results of Research}

The student performance throughout the teaching and learning sequence (TLS) is shown in Figure 3, with respect to the symbolic aspect that was analyzed and discussed in this article. 


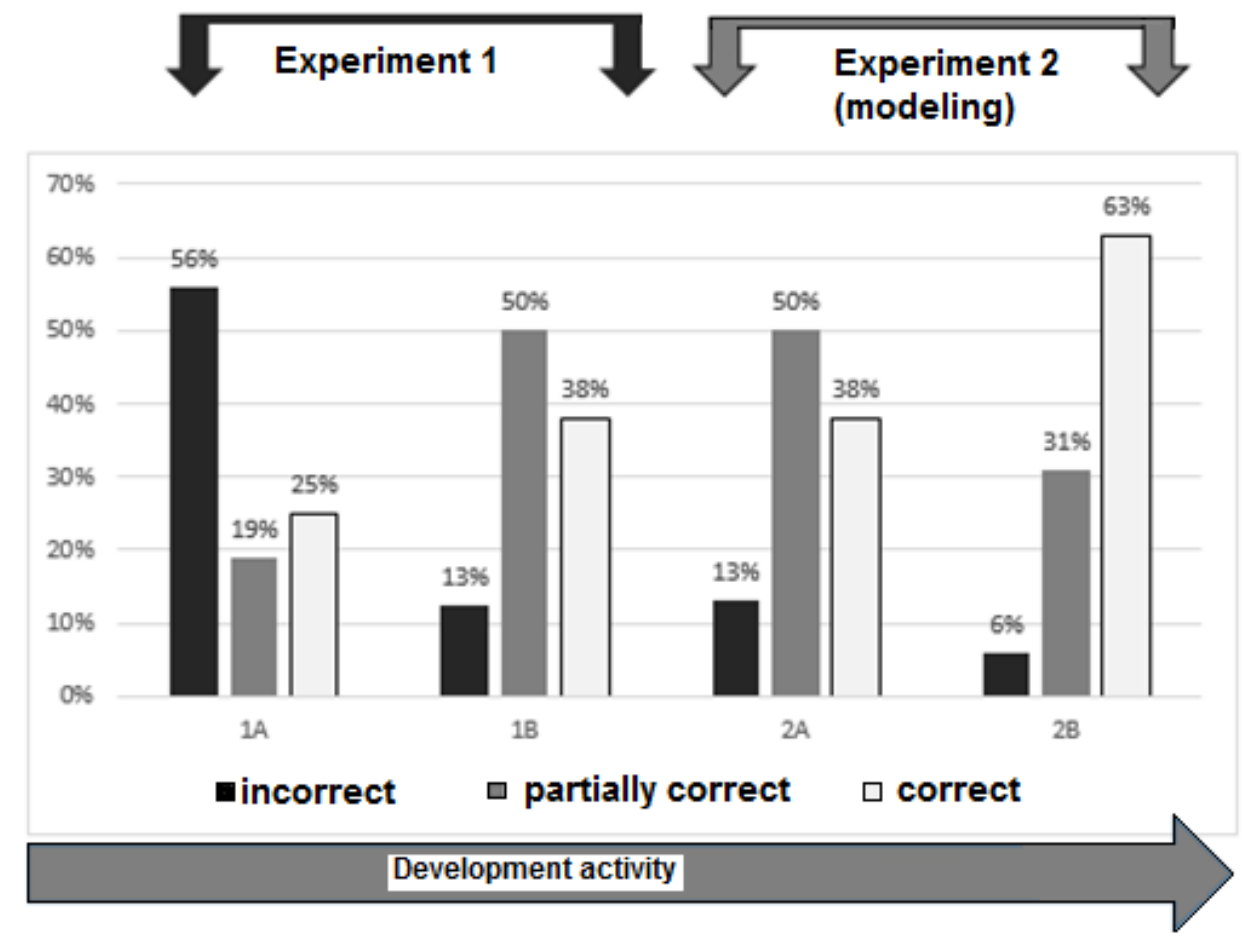

Figure 3: Performance of students.

The Figure 3 shows an overall increase in correct representation over the span of the teaching and learning sequence; consequently, there is a decrease in the incorrect representation.

First, they had to propose a chemical equation for the observed phenomenon (part 1A) and to rethink it (part 1B), making possible the reconstruction of the ideas, in the table 2 are two examples of the results (part 1A):

Table 2. Examples of the chemical equation prepared by the students for the $1^{\text {st }}$ experiment.

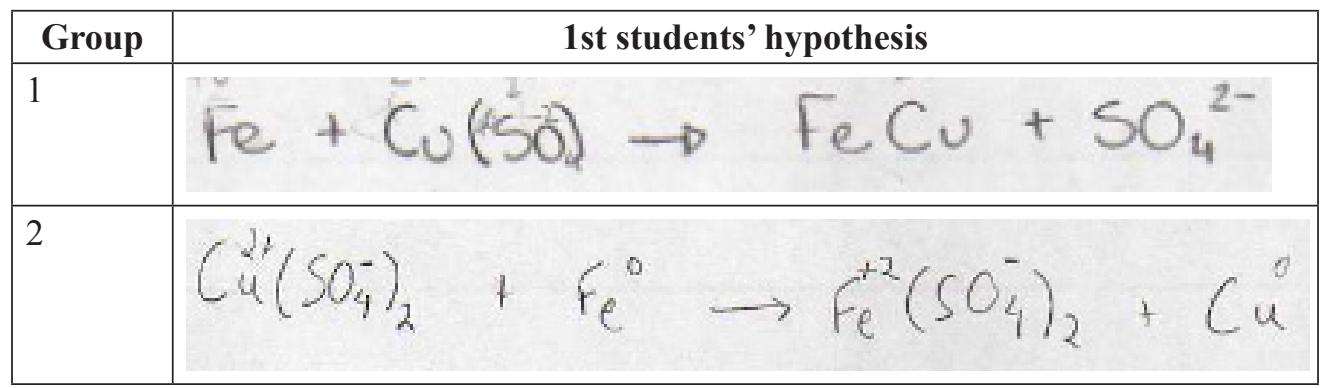


Thereby, this is the initial hypothesis proposed by the students regarding iron and copper ion interaction. In sequence, the metavisual step (1B), wherein they were able to rebuild or ratify ideas.

After this first time (Experiment 1), they were able to model and build a better explanatory model in experiment 2 , since they had already built and rebuilt over the first. Then, they proposed the hypothesis again, now with respect to iron and aqueous sulfuric acid interaction $(2 \mathrm{~A})$ and the metavisual step again $(2 \mathrm{~B})$ - in the table 3 there are two examples of the results $(2 \mathrm{~A})$.

Table 3. Examples of the chemical equation prepared by the students for the $2^{\text {nd }}$ experiment.

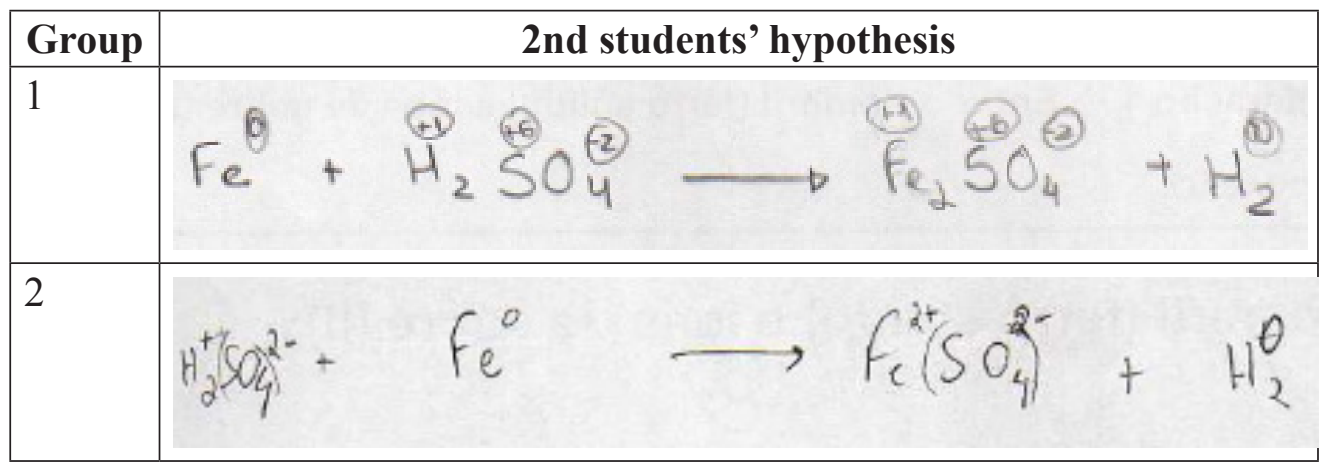

\section{Discussion}

The results provide an overview of the students' performance, from the first proposition of hypotheses for a symbolic explanation for the experiment 1 (1A), the rethinking about it (1B) and the same for the experiment 2 (symbolic 2A and 2B). In a general way, with respect to Experiment 1, with respect to the data it is observed that there was a reduction of incorrect assumptions, from $56 \%$ to $13 \%$, increasing the number of partially correct from $19 \%$ to $50 \%$ and increasing the number of correct $25 \%$ to $38 \%$. Regarding the Experiment 2 , the students began with a much smaller number of incorrect assumptions and even decreased during the process, from $13 \%$ to $6 \%$. They started with $50 \%$ of partially correct assumptions, reducing this number to $31 \%$ and the number of correct answers increased from $38 \%$ to $63 \%$. Thus, it is observed that, for both the first and second experiment, there was a good performance of explanatory models proposed by students. This is especially important, as pointed out by Obomanu \& Onuoha, (2012) regarding the correct understanding of equations, reported in their work, wherein $50 \%$ of students had difficulty in this item. In this paper, it was found, for example, one group who had proposed the following chemical equation (Part 2A) (Figure 4):

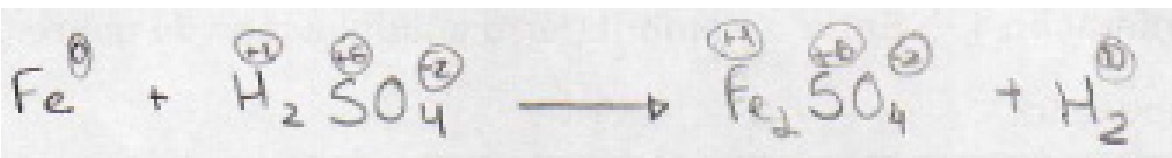

Figure 4: Representation proposed by students for the experiment 2. 
By observing the image, the students realized that the iron charge would be +2 instead of +1 , correcting the formula " $\mathrm{Fe}_{2} \mathrm{SO}_{4}$ " (Part 2B).

Likewise, another group had proposed the following chemical equation (Figure 5):

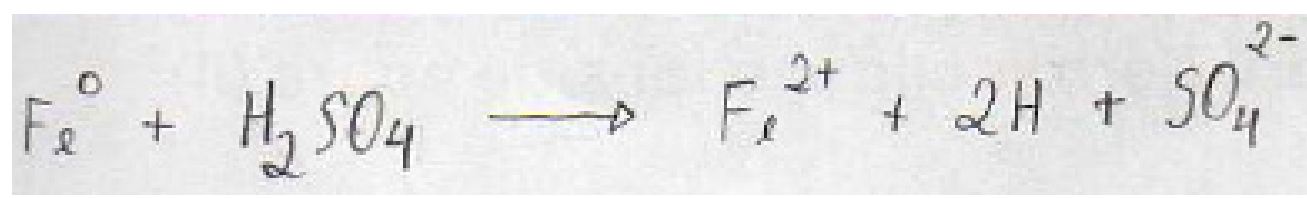

Figure 5: Another representation proposed by students for the experiment 2.

After the metavisual stage, they were able to recognize that the product would be hydrogen gas, which is represented by diatomic molecules $\mathrm{H}_{2}$ instead of "2H". This strengthens what Tabet (2009) points out that sometimes students are thinking right, but cannot express it in symbols, as shown in the speech of the student to compare the image presented to them and the equation proposed by them, that was written " $2 \mathrm{H}$ " instead of $\mathrm{H}_{2}$ : "Oh, actually forms the gas, which will come out of the substance, and we adjusted the iron before and after, just missed the $\mathrm{H}$ at the end (referring to $2 \mathrm{H}$ ). It had to be $\mathrm{H}_{2}$ and not $2 \mathrm{H}$, which is the hydrogen gas, is not it?" Then, improving initial understanding of the concepts of electrochemistry, it can allow better learning of the contents of these topics, which are seen as difficult in general in several works in the area (Obomanu \& Onuoha, 2012; Rosenthal \& Sanger, 2012; Schmidt, Marohn \& Harrison, 2007), about conceptions and difficulties, as mentioned.

As suggested by Justi, Gilbert \& Ferreira (2009) the time to rethink, which is essentially metacognitive (the rethinking - Parts B teaching and learning sequence) provides the students include aspects in their assumptions that had not considered and thus, it will shape their thoughts. Chittleborough \& Treagust (2008) confirm this by saying that it is not always explicit the student make the connections of the various representational levels, then metavisual strategy may have helped in this process. In addition, in general, it is what was found in this work, this reconstruction of ideas, as can be seen in Figure 3.

It was observed a qualitative improvement in the results comparing the first with the second experiment, with a reduction of incorrect propositions, from $56 \%$ to $6 \%$ and increased correct propositions from $25 \%$ to $63 \%$. This was already somewhat expected due to the modeling process, as stressed Justi, Gilbert \& Ferreira (2009) in which the modeling strategy leads students to good levels of understanding, specifically regarding the metavisualization, also pointed out by Locatelli \& Arroio (2013). In the first experiment, 38\% of students managed to equate or understand the equation, and in the second experiment that number rose to $63 \%$, which can be explained partly by the modeling process afforded by metavisual strategy. There is an example of representation made by students regarding the experiment 1 (Figure 6):

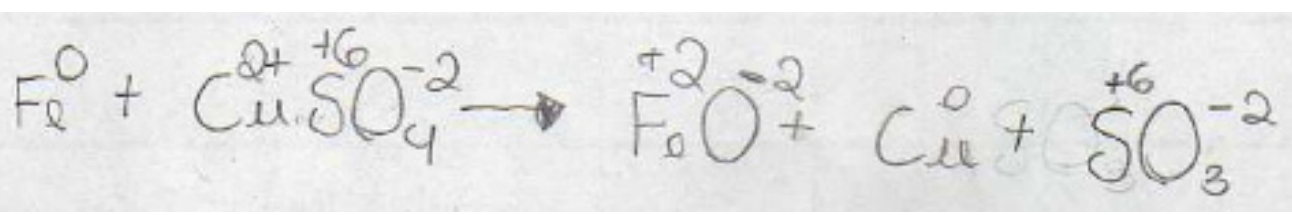

Figure 6: Representation made by students. 
Revealing that the group had difficulty to propose a hypothesis for the phenomenon. However, this same group proposed to the second experiment the following hypothesis (Figure 7):

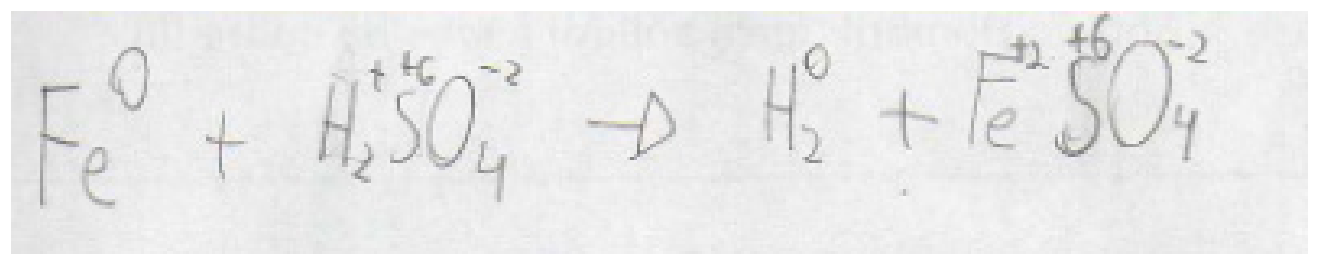

Figure 7: Representation made by students regarding the experiment 2.

This evidences that perhaps they have managed to understand and model their understanding.

It is important to emphasize the fundamental role of the teacher as process mediator (Justi, Gilbert \& Ferreira, 2009) because he only made greater interference after this teaching and learning sequence (TLS), resuming with students and making a dialogue discussion. This can justify that still part of students $(6 \%)$ have failed to equate the process at this stage and $31 \%$ were only partially achieved. Also, regarding the figure 3 , it is important to note that initially $56 \%$ of the proposals were incorrect, and at the end that fell to $6 \%$, which corresponds to a single group that failed to increase its ranking. Moreover, $25 \%$ of proposals were correct initially and at the end, the number has increased to $63 \%$. Finally, $19 \%$ were partially correct, reaching $31 \%$. These research data provide an indication that the metavisual strategy may have helped in the reconstruction of ideas, as pointed Locatelli, Ferreira \& Arroio (2010), Gilbert (2005) and Chittleborough \& Treagust (2008). This is because metacognition involves the possibility of self-regulation of cognitive processes, to the extent that students think about their knowledge (Flavell, 1976).

\section{Conclusions}

Regarding the research question: To what extent to rethink images may contribute to (re) construction of explanatory models in the symbolic level? It has evidence that metavisual strategy used to compare drawings seeking differences and similarities, may have contributed to a better understanding of the concepts, as can be seen by the results. Thus, metacognitive activities that allow the modeling can be very important for learning, both to start the study of a topic, and for further discussion. This is due to the teaching and learning sequence. (TLS) allows students to succeed explain their misconceptions and discuss them with their peers in an active construction process. Regarding the symbolic level that has already been analyzed, $38 \%$ of students managed to rebuild their ideas in the first experiment, increasing to $63 \%$, wherein they were able to self-regulate in the second one, only one group (6\%) failed to advance, and this was without a direct mediation of the teacher, what happened next. This may indicate that the metavisual strategy used is important from the point of view of teaching and learning, because the misconceptions that are common in electrochemical teaching might be, to some extent, taken up and redirected. However, it may be pointed out again here that further discussion mediated by the teacher is important, since not all students are able to rebuild their ideas properly. It is also recommended that more studies could be done primarily to verify to what extent metavisual strategies can aid learning in science and the factors that are involved in this process. 


\section{Acknowledgements}

The authors acknowledge the 32 students of the 3rd year of high school (2015) by the readiness and collaboration in joining the research and the school that made possible the development of these activities.

\section{References}

Chittleborough, G., \& Treagust, D. (2008). Correct interpretation of chemical diagrams requires transforming from one level of representation to another. Research Science Educational, 38, 463-482.

Ericsson, K. A., \& Simon, H. A. (1993). Protocols analysis, verbal report as data. United States of America: Bradford Book.

Flavell, J. H. (1976). Metacognitive aspects of problem solving. In L.B. Resnick (Eds.), The nature of intelligence (pp. 231-235). Hillsdale, N.Y.: Erlbaum.

Gilbert, J. K. (2005). Visualization: A metacognitive skill in science and science education. In J. K. Gilbert (Eds.), Visualization in science education (pp. 9-27). Holland: Springer.

Gilbert, J. K., \& Treagust, D. F. (2009). Introduction: Macro, submicro and symbolic representations and the relationship between them: key models in chemical education. In: J. K. Gilbert, D. Treagust (Eds.), Multiple representations in chemical education (pp. 1-8). Dordrecht: Springer.

Justi, R., Gilbert, J. K., \& Ferreira, P. F. M. (2009). The application of a "model of modelling" to illustrate the importance of metavisualization in respect of the three types of representation. In: J. K. Gilbert, D. Treagust (Eds.), Multiple representations in chemical education (pp. 285-307). Dordrecht: Springer.

Locatelli, S., \& Arroio, A. (2013). Metacognition and chemical education: An experience in teaching geometrical isomerism. Gamtamokslinis ugdymas / Natural Science Education, 37 (2), 18-26.

Locatelli, S., Ferreira, C., \& Arroio, A. (2010). Metavisualization: An important skill in the learning chemistry. Problems of Education in the $21^{\text {st }}$ Century, 24, 75-83.

Obomanu, B. J., \& Onuoha, C. O. (2012). Students conceptual difficulties in electrochemistry in senior secondary schools. Journal of Emerging Trends in Educational Research and Policy Studies, 3 (1), 99-102.

Rosenthal, D., \& Sanger, M. (2012). Student misinterpretations and misconceptions based on their explanations of two computer animations of varying complexity depicting the same oxidation-reduction reaction. Chemistry Education Research and Practice, 13, 471-483.

Schmidt, H. J., Marohn, A., \& Harrison, A. G. (2007). Factors that prevent learning in electrochemistry. Journal of Research in Science Teaching, 44 (2), 258-283.

Taber, K. S. (2009). Learning at the symbolic level. In: J. K. Gilbert, D. Treagust (Eds.), Multiple representations in chemical education (pp. 75-104), Dordrecht: Springer. 


\section{Solange Locatelli}

PhD. Student, Chemistry Teacher, Faculty of Education, University of São Paulo, São Paulo, Brazil. E-mail: solangewl@hotmail.com

Website: http://usp-br.academia.edu/SolangeLocatelli

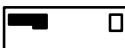

\section{Agnaldo Arroio}

PhD., Professor, Faculty of Education, University of São Paulo, São Paulo, Brazil.

E-mail: agnaldoarroio@yahoo.com

Website: http://usp-br.academia.edu/AgnaldoArroio 